Ihab Kaddoura, Lars Kröger, Kai Nagel

\title{
User-specific and Dynamic Internalization of Road Traffic Noise Exposures
}

Dokumententyp | Accepted manuscript (Postprint)

This version is available at https://doi.org/10.14279/depositonce-8232

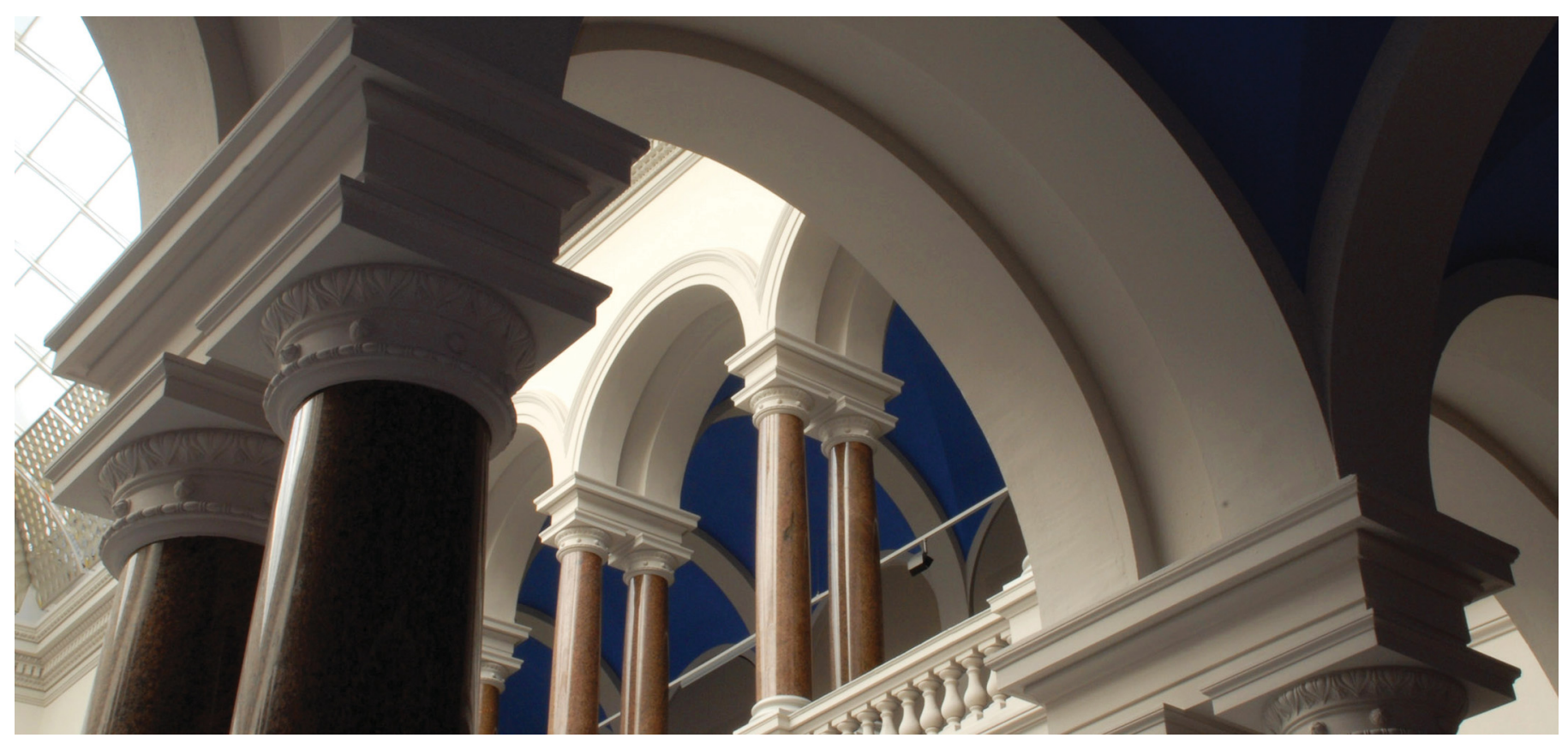

This is a post-peer-review, pre-copyedit version of an article published in Networks and Spatial Economics. The final authenticated version is available online at: http://dx.doi.org/10.1007/s11067-016-9321-2.

Kaddoura, I.; Kröger, L.; Nagel, K. (2016). User-specific and Dynamic Internalization of Road Traffic Noise Exposures. Networks and Spatial Economics, 17(1), 153-172.

https://doi.org/10.1007/s11067-016-9321-2 


\title{
User-specific and dynamic internalization of road traffic noise exposures
}

\author{
Ihab Kaddoura · Lars Kröger · Kai Nagel
}

The final publication is available at link.springer.com.

Preferred citation style: Kaddoura, I., L. Kröger and K. Nagel. User-specific and dynamic internalization of road traffic noise exposures. Networks and Spatial Economics, 2016. doi: 10.1007/s11067-016-9321-2

Received: date / Accepted: date

\begin{abstract}
In this study, a noise internalization approach is presented and successfully applied to a real-world case study of the Greater Berlin area. The proposed approach uses an activity-based transport simulation to compute noise levels and population densities as well as to assign noise damages back to road segments and transport users. Iteratively, road segment and time dependent noise exposure tolls are computed to which transport users can react by adjusting their route choice decisions. Since tolls correspond to the transport user's contribution to the overall noise exposures, the incentives are given to change individual travel behavior towards reduced noise exposure costs. Applying the internalization approach to the case study reveals that transport users shift from minor to major roads and take detours in order to avoid areas with high population densities. The contribution of the presented methodology is that the within day dynamics of varying population densities in different areas of the city are explicitly taken into account and affected people at work and places of education may be incorporated, which is both found to have a major impact on toll levels and network utilization. Depending on the time of day and depending on which population groups are considered, noise exposures are reduced by means of different traffic management strategies.
\end{abstract}

Keywords Road Traffic Noise · Internalization · Pricing · Dynamic Tolling · Exposure Analysis · Noise Control · Traffic Management · Activity-based Transport Modeling

I. Kaddoura $\cdot$ K. Nagel

Technische Universität Berlin; Department of Transportation System Planning and Telematics; Sekr. SG 12; Salzufer 17-19; 10587 Berlin; Germany

Tel.: +49-30-314-787-93

Fax: +49-30-314-262-69

E-mail: kaddoura@vsp.tu-berlin.de

L. Kröger

German Aerospace Center; Institute of Transport Research; Rutherfordstr. 2; 12489 Berlin; Germany 


\section{Introduction and problem statement}

Many studies prove that environmental noise causes cardiovascular diseases, tinnitus, cognitive impairment and sleep disturbances (see, e.g., Ising et al 1996: Stassen et al, 2008; WHO Europe, 2009, 2011; Babisch et al, 2013). This negative impact on public health is addressed by a vast number of noise control measures. Encouraging the use of quieter vehicles (e.g. improved aerodynamics, tires or motor engines), the building of noise barriers, and improved road surfaces, aim to reduce noise exposures. They do, however, not affect the origin of the sound, namely the travel behavior. Traffic control measures allow for a reduction in noise exposures by changing the travel behavior, e.g. the transport route, the mode of transportation, the departure time. Possible means to rearrange traffic flows towards a higher system efficiency are, for example, reduced speed levels, turn restrictions or pricing schemes. The economic principle of optimal price setting by means of internalizing external effects has been widely studied in the literature (Vickrey, 1969, Arnott et al 1994 de Palma and Lindsey, 2004, Friesz et al, 2004). In order to prioritize various noise control measures and to quantify external noise cost which may be internalized, the number of individuals that are exposed to certain noise levels is of major importance. Traffic management strategies should ideally consider both, the reduction in noise exposures and the avoidance costs such as increased travel times from driving detours (see, e.g. Lin et al, 2014).

Most noise mapping and action planning approaches focus on residential noise exposures based on estimates for the number of residents per building (see, e.g. SenStadt, 2012, DEFRA, 2015, Gulliver et al, 2015). This is a reasonable approach for nightly exposures (see, e.g., BVU et al, 2003 , pp. 187-189). However, static resident numbers are difficult to be used for the computation of noise exposures during daytime as residents leave the house to perform other activities located in other areas.

A review of several noise regulations reveals that estimates for the number of exposed individuals should not be limited to residents at their home location. Tab. 1 depicts limit values of the A-weighted and time-averaged traffic sound level for different land-use types such as hospitals or commercial areas based on the German 16 . BImSchV] In context of noise protection at the work-

Table 1: Outdoor noise limit values based on $16 . \mathrm{BImSchV}$

\begin{tabular}{ll}
\hline Land use type & Limit value (day/night) \\
\hline hospitals, schools, sanatoriums, retirement homes & $57 \mathrm{~dB}(\mathrm{~A}) / 47 \mathrm{~dB}(\mathrm{~A})$ \\
residential areas & $59 \mathrm{~dB}(\mathrm{~A}) / 49 \mathrm{~dB}(\mathrm{~A})$ \\
mixed residential/commercial areas & $64 \mathrm{~dB}(\mathrm{~A}) / 54 \mathrm{~dB}(\mathrm{~A})$ \\
commercial areas & $69 \mathrm{~dB}(\mathrm{~A}) / 59 \mathrm{~dB}(\mathrm{~A})$ \\
\hline
\end{tabular}

place, noise limit values include noise sources from inside the workplace and 
therefore refer to the indoor sound level. As an international standard adopted at European and German level, the DIN EN ISO 11690-1 recommends noise limit values depending on the indoor work type, depicted in Tab. 2, To trans-

Table 2: Indoor noise limit values based on DIN EN ISO 11690-1

\begin{tabular}{ll}
\hline Indoor type & Limit value \\
\hline Conference room & $30-35 \mathrm{~dB}(\mathrm{~A})$ \\
Classroom, Single office & $30-40 \mathrm{~dB}(\mathrm{~A})$ \\
Open space office & $35-45 \mathrm{~dB}(\mathrm{~A})$ \\
Industrial laboratories and control rooms & $35-55 \mathrm{~dB}(\mathrm{~A})$ \\
Industrial workspace & $65-70 \mathrm{~dB}(\mathrm{~A})$ \\
\hline
\end{tabular}

late indoor noise levels to the outside facade, the insulation effect of buildings needs to be considered. The insulation effect of a building depends on several factors such as the wall material and thickness, the window number and sizes, and the glazing technology. Furthermore, indoor noise levels depend on whether windows are opened or closed, which is found to be particularly relevant for bedrooms during the night (WHO Europe, 2009). Depending on the type of window, the noise reduction of a closed window ranges from approximately $25 \mathrm{~dB}$ to $48 \mathrm{~dB}$ (see, e.g. DIN 4109, Beiblatt 1, p. 55-56). Whereas opened windows have an effect of $5 \mathrm{~dB}$ sound reduction, tilted-open windows reduce the sound level by approximately $15 \mathrm{~dB}$ (see, e.g. RPS, 2011, Appendix 8 ). Overall, the above described regulations and limit values indicate the importance to go beyond residential noise exposures and to explicitly account for individuals affected by noise at work or educational activities, i.e. at school or university.

In the same context, the Environmental Noise Directive of the European Union 2002/49/EC explicitly mentions certain building types, i.e. schools and hospitals, indicating that noise exposure analysis should not be limited to residents at their home location. However, the data to be delivered to the European Commission specified in 2002/49/EC, App. 6, and the 'Good Practice Guide for Strategic Noise mapping and the Production of Associated Data on Noise Exposures' only refer to residential noise exposures (WG-AEN, 2006).

Several studies address the absence of a standardized methodology to calculate noise exposures and set priorities for action planning in the European Union (see, e.g., Murphy and King, 2010, Ruiz-Padillo et al, 2014). Lam and Chung (2012) show that a differentiated analysis of residential noise exposures provides interesting insights. The authors analyzed the population exposures with regard to socio-economic characteristics and find older and less educated residents in Hong Kong to be worst affected by traffic noise. Murphy and King (2010) address the importance to account for the day-to-day dynamics of varying population densities, i.e. weekend commuters. In contrast, the authors do not mention the within day dynamics of varying population den- 
sities (e.g. daily commuters). Ruiz-Padillo et al (2014) propose an approach to compute a road stretch-specific priority index that can be used for noise control action planning. The index sorts road stretches by their noise problems, i.e. taking into consideration the noise level as well as the number of exposed residents. Furthermore, the priority index considers the "occurrence of noise sensitive centers" such as educational, cultural or health facilities. In Tenaileau et al (2015), the authors address the size of the local living neighborhood to calculate residential noise exposures. The authors describe this exposure area to be usually limited to the home location, and in case outdoor exposures are accounted for, to be enlarged to the relevant neighborhood. The authors' conclusion is that their current approach should be revised to account for the population's variability in the daily activity and travel behavior. The authors suggest that population exposures should ideally be computed for each individual separately. Gühnemann et al (2014) discuss optimal pricing strategies to protect sensitive areas. The authors find that prices should be regulated globally and account for all sensitive areas. Furthermore, the authors address the importance to consider the impact of noise on recreational activities. Lin et al (2014) address traffic management strategies designed to meet hard environmental constraints. The authors present a criterion which can be used to assess traffic control measures regarding their impact on the network performance. In context of air pollution, Hatzopoulou and Miller (2010) and Kickhöfer and Kern (2015) have pointed out the importance to account for the temporal and spatial variability in air quality and population density. Similar to the latter study, Kaddoura et al (2015) propose an approach to compute noise exposures which explicitly considers the within day dynamics of varying population densities in different areas of the city and incorporates individuals that may be affected at work, university or school, which is both found to have a substantial effect on the quantification of noise exposures.

In this paper, a user-specific and dynamic pricing approach is proposed to internalize road traffic noise damages. The computation of noise exposures follows the methodology described in Kaddoura et al (2015). The proposed pricing approach uses an activity-based transport simulation to compute noise levels and population densities as well as to assign noise damages back to road segments and transport users. Iteratively, road segment and time dependent noise exposure tolls are computed to which transport users can react. Since tolls correspond to the transport user's contribution to the overall noise exposures, the incentives are given to change users' travel behavior towards a higher system efficiency. The presented approach can be used for noise control action planning, i.e. how to manage traffic to reduce noise exposures while keeping the avoidance costs low. Thereby, the proposed approach explicitly accounts for the temporal and spatial variation of the noise level and population density. Furthermore, noise exposures are quantified taking into consideration people that are exposed to traffic noise at work or educational activities. The innovative pricing approach is applied to the case study of the Greater Berlin area. 
The remainder of the paper is organized as follows: Sec. 2 describes the applied transport simulation framework and the noise internalization approach. Sec. 3 provides the setup of the Berlin case study which is used for two pricing experiments. The simulation outcome is analyzed and discussed in Sec. 4 and Sec. 5. Finally, Sec. 6 provides the conclusions for policy makers and an outlook on future research.

\section{Methodology}

\subsection{Transport simulation framework}

The proposed pricing approach uses the open-source simulation framework MATSim ${ }^{1}$ to compute noise levels and population exposures and to investigate the changes in travel demand as a response to the pricing policy. As an activity-based transport model, MATSim contains the number of individuals including the distribution of specific activities (e.g. home, work, school) for each temporal and spatial unit. The demand for transport results from spatially separated activity locations. The demand side is represented by individual agents. In a preliminary step, for each agent initial travel plans have to be generated describing the sequence of daily activities (e.g. home-workleisure-home) as well as initial transport modes and departure times for the trips between one activity (location) and the next one. The adaptation of demand to supply follows an evolutionary iterative approach involving (1) the traffic flow simulation, (2) an evaluation of executed plans and (3) learning.

1. Traffic Flow Simulation All agents execute their travel plans simultaneously and interact in the physical environment. The vehicles' movements along road segments (links) follow the queue model developed by Gawron (1998) considering each link as a First In First Out queue with certain attributes, i.e. a free speed travel time, a flow capacity, and a storage capacity (causing spill-back effects). The resulting flows of traffic are consistent with the fundamental diagram (see e.g. Agarwal et al, 2015).

2. Evaluation Each executed plan is scored based on predefined behavioral parameters. A plan's score is typically composed of two parts, the travel cost (e.g. travel time, monetary payments) and the utility gained from activity performing. The latter part is computed as follows:

$$
V_{a}=\beta_{p e r f} \cdot t_{t y p, a} \cdot \ln \left(\frac{t_{p e r f, a}}{t_{0, a}}\right)
$$

where $V_{a}$ is the utility gained from performing activity $a, t_{\text {perf }}$ is the duration performing an activity, $t_{t y p, a}$ is an activity's "typical" duration, $\beta_{a c t}$ is the marginal utility of performing an activity at its typical duration, and $t_{0, a}$ is a scale parameter which is not relevant in this study since activities cannot be dropped from the daily travel plans (see Charypar and Nagel. 2005).

1 Multi-Agent Transport Simulation, see www.matsim.org 
3. Learning Every iteration, a certain share of agents generate new plans by creating a copy of an existing plan and modifying it, for example changing the route. The other agents select a plan to be executed in the next iteration by choosing among their existing plans based on a multinomial logit model.

Iteratively repeating the above steps allows the agents to improve, obtain plausible travel plans, and the simulation results stabilize. Assuming the agents' travel plans to represent valid choice sets, the system state converges towards the stochastic user equilibrium (Nagel and Flötteröd, 2012). A detailed description of the simulation framework is provided in Raney et al (2003) and Raney and Nagel (2006).

2.2 Internalization of road traffic noise damages

The presented approach to compute and internalize road traffic noise damages is visualized in Fig. 1. In the first module, the noise emissions are calculated

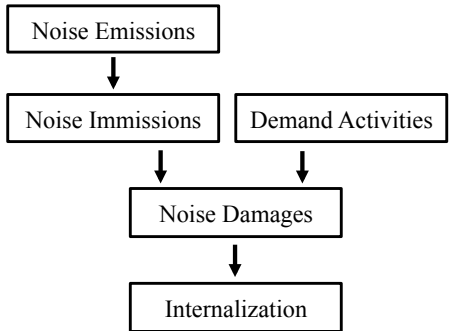

Fig. 1: Computation modules

based on the traffic flow, HGV share and the speed level. The second module computes the noise immissions for a predefined set of receiver points. The third computation module follows all individuals' daily activities (locations and activity start and end times). Both, the noise immissions and demand activities are required by the fourth module which computes individual damage costs. The fifth module assigns the damages back to the road segments and vehicles. Sec. 2.2.1 summarizes the first four modules, i.e. how noise damages are calculated (for a detailed description, see Kaddoura et al, 2015). Sec. 2.2.2 describes the newly introduced internalization module, i.e. how noise damages are mapped back to road segments and vehicles. 


\subsubsection{Calculation of noise damages}

Noise emission levels are calculated for each road segment $i$ and time interval $t$ with

$$
E_{i, t}=E_{i, t}^{25}+D_{i}^{v}
$$

where $E_{i, t}$ denotes the resulting average noise emission level in $\mathrm{dB}(\mathrm{A})$ calculated based on the German RLS-90 approach ('Richtlinien für den Lärmschutz an Straßen', FGSV, 1992); and $E_{i, t}^{25}$ is the average sound level in $\mathrm{dB}(\mathrm{A})$ for a set of predefined conditions, i.e. a horizontal distance of 25 meters, a height difference of 2.25 meters and a maximum speed of $100 \mathrm{~km} / \mathrm{h}$, smooth asphalt road surface, a gradient of less than 5\%; with

$$
E_{i, t}^{25}=37.3+10 \cdot \log _{10}\left[M_{i, t} \cdot\left(1+0.082 \cdot p_{i, t}\right)\right],
$$

where $M_{i, t}$ is the traffic volume; $p_{i, t}$ is the HGV share in $\% . D_{i}^{v}$ is the speed correction calculated as

$$
D_{i}^{v}=E_{i}^{c a r}-37.3+10 \cdot \log _{10}\left[\frac{100+\left(10^{0.1 \cdot\left(E_{i}^{h g v}-E_{i}^{c a r}\right)}-1\right) \cdot p_{i, t}}{100+8.23 \cdot p_{i, t}}\right],
$$

with

$$
\begin{gathered}
E_{i}^{c a r}=27.7+10 \cdot \log _{10}\left[1+\left(0.02 \cdot v_{i}^{c a r}\right)^{3}\right] \\
E_{i}^{h g v}=23.1+12.5 \cdot \log _{10}\left(v_{i}^{h g v}\right),
\end{gathered}
$$

where $v_{i}^{\text {car }}$ denotes the maximum speed for passenger cars in kilometers per hour; and $v_{i}^{h g v}$ denotes the maximum speed for HGV in kilometers per hour. Noise immission levels are calculated for a grid of receiver points and updated every time interval. The noise superposition for a single receiver point $j$ is

$$
I_{j, t}=10 \cdot \log _{10} \sum_{i} 10^{0.1 \cdot I_{i, j, t}} \quad\left\{I_{i, j, t}>0\right\}
$$

with

$$
I_{i, j, t}=E_{i, t}+D_{i, j}^{d}+D_{i, j}^{\alpha},
$$

where $I_{j, t}$ is the total noise immission level in $\mathrm{dB}(\mathrm{A}) ; I_{i, j, t}$ denotes the noise immission level in $\mathrm{dB}(\mathrm{A})$ resulting from road segment $i ; D_{i, j}^{d}$ is the noise correction in $\mathrm{dB}(\mathrm{A})$ due to air absorption which follows the RLS-90 approach 'lange, gerade Fahrstreifen' ('long, straight lanes'), with

$$
D_{i, j}^{d}=15.8-10 \cdot \log _{10}\left(d_{i, j}\right)-0.0142 \cdot d_{i, j}^{0.9},
$$

where $d_{i, j}$ is the shortest distance between the road segment $i$ and the receiver point $j$ in meters (minimally 5 meters). $D_{i, j}^{\alpha}$ denotes the correction for the road segment's length in $\mathrm{dB}(\mathrm{A})$ following Nielsen et al (1996), with

$$
D_{i, j}^{\alpha}=10 \cdot \log _{10}\left(\frac{\alpha}{180}\right)
$$


where $\alpha$ is the angle from receiver point $j$ to road segment $i$ in degrees. To ensure a fast computational performance and reduce the required input data, in this study, further corrections which take into account e.g. other road surfaces, road gradients, multiple reflections or shielding of buildings are not accounted for. Furthermore, for each receiver point, only the road segments with any section within the range of 500 meters are considered. The spatial and temporal variation in the population is computed as

$$
N_{j, t}=\sum_{n} \frac{a_{n, j, t}}{T}
$$

where $N_{j, t}$ denotes number of demand units that may be exposed to noise at receiver point $j$ in time interval $t ; n$ is the individual person; $a_{n, j, t}$ is the duration person $n$ performs an activity of a considered type (e.g. 'home') at a location which is assigned to receiver point $j$; and $T$ is the duration of the time interval $t$ in seconds. Noise damages per receiver point $j$ and time interval $t$ are calculated as

$$
C_{j, t}=\left\{\begin{array}{ll}
c^{T} \cdot N_{j, t} \cdot 2^{0.1 \cdot\left(I_{j, t}-I_{t}^{\min }\right)} & I_{j, t} \geq I_{t}^{\min } \\
0 & I_{j, t}<I_{t}^{\text {min }}
\end{array},\right.
$$

with

$$
c^{T}=c^{\text {annual }} \cdot \frac{T}{(365 \cdot 24 \cdot 3600)},
$$

where $C_{j, t}$ denotes the noise damage costs in monetary units; $c^{T}$ is the cost rate in monetary units per $\mathrm{dB}(\mathrm{A})$ that is exposed to one demand unit for the duration $T ; c^{\text {annual }}$ is the annual cost rate which, in this study, is equal for all affected individuals and set to $63.3 \mathrm{EUR}^{2}$, and $I_{t}^{\text {min }}$ is the threshold immission level in $\mathrm{dB}(\mathrm{A})$ which depends on the time of day. The applied approach follows the threshold-based German EWS approach (FGSV, 1997) and noise threshold values are assumed to be the same for all parts of the population and activity types. In this study, the threshold values are set to $50 \mathrm{~dB}(\mathrm{~A})$ for time intervals during the day (6 a.m. to 6 p.m.), $45 \mathrm{~dB}(\mathrm{~A})$ for time intervals during the evening (6 p.m. to 10 p.m.) and $40 \mathrm{~dB}(\mathrm{~A})$ for time intervals during the night (10 p.m. to 6 a.m.).

\subsubsection{Assigning noise damage costs to links and vehicles}

The following approach to assign noise damage costs back to the causing agents is based on Gerike et al (2012) in which the computation methods are provided, but where no numerical examples are presented. The approach considers the logarithmic scale of noise and computes the contribution of each road segment and vehicle to the overall noise damage costs. An overview of the internalization methodology applied in this study is given in Fig. 2. In a first step,

\footnotetext{
2 This value is based on the annual cost rate of 85 DM (Deutsche Mark) which is given in the EWS ('Empfehlungen für Wirtschaftlichkeitsuntersuchungen an Straßen' FGSV], 1997) for the year 1995, converted into EUR, and updated with an annual interest rate of $2 \%$. The cost rate considers the avoidance costs for noise during the night and the willingness-to-pay for reduced noise levels during the day (FGSV, 1997, p. 14).
} 


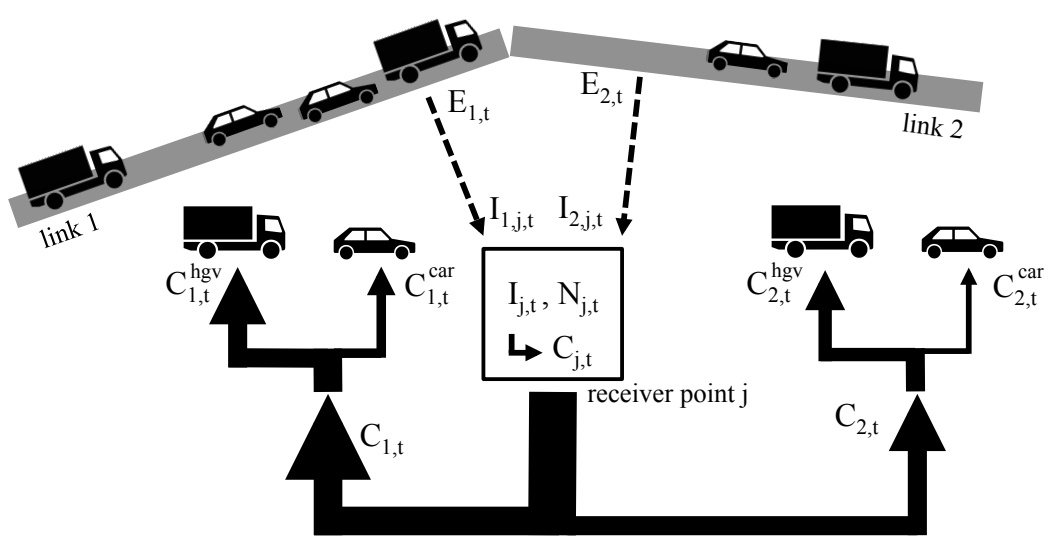

Fig. 2: Back-mapping of noise damage costs to links and vehicles; the widths of the solid arrows represent the approximate assigned costs

the receiver points' damage costs are assigned to the road segments. A road segment's total contribution to the overall noise damage costs is

$$
C_{i, t}=\sum_{j} S_{i, j, t} \cdot C_{j, t}
$$

with

$$
S_{i, j, t}=\left(\frac{10^{0.05 \cdot I_{i, j, t}}}{10^{0.05 \cdot I_{j, t}}}\right)^{2},
$$

where $C_{i, t}$ is the total contribution of road segment $i$ to the overall noise damages at the surrounding receiver points; and $S_{i, j, t}$ is the share of road segment $i$ to the overall noise damage costs at receiver point $j$ during time interval $t$ (Gerike et al, 2012 , Eq. 2).

In a second step, the road segment's total contribution is allocated to the different vehicle types (Gerike et al, 2012, Eq. 5 and 6). The costs assigned to each vehicle type are

$$
\begin{gathered}
C_{i, t}^{c a r}=S_{i, t}^{c a r} \cdot C_{i, t} \\
C_{i, t}^{h g v}=S_{i, t}^{h g v} \cdot C_{i, t},
\end{gathered}
$$

with

$$
\begin{aligned}
S_{i, t}^{c a r} & =\frac{M_{i, t} \cdot\left(1-\frac{p_{i, t}}{100}\right) \cdot 10^{0.1 \cdot E_{i}^{c a r}}}{M_{i, t} \cdot\left(1-\frac{p_{i, t}}{100}\right) \cdot 10^{0.1 \cdot E_{i}^{c a r}}+M_{i, t} \cdot\left(\frac{p_{i, t}}{100}\right) \cdot 10^{0.1 \cdot E_{i}^{h g v}}} \\
S_{i, t}^{h g v} & =\frac{M_{i, t} \cdot\left(\frac{p_{i, t}}{100}\right) \cdot 10^{0.1 \cdot E_{i}^{h g v}}}{M_{i, t} \cdot\left(1-\frac{p_{i, t}}{100}\right) \cdot 10^{0.1 \cdot E_{i}^{c a r}}+M_{i, t} \cdot\left(\frac{p_{i, t}}{100}\right) \cdot 10^{0.1 \cdot E_{i}^{h g v}}},
\end{aligned}
$$

where $C_{i, t}^{c a r}$ and $C_{i, t}^{h g v}$ are the costs assigned to each vehicle type (passenger car or $\mathrm{HGV}$ ); and $S_{i, t}^{c a r}$ and $S_{i, t}^{h g v}$ are the noise shares for each vehicle type on road segment $i$ during the time interval $t$. 
Finally, the costs allocated to single vehicles are

$$
\begin{gathered}
c_{i, t}^{c a r}=\frac{C_{i, t}^{c a r}}{M_{i, t} \cdot\left(1-\frac{p_{i, t}}{100}\right)} \\
c_{i, t}^{h g v}=\frac{C_{i, t}^{h g v}}{M_{i, t} \cdot\left(\frac{p_{i, t}}{100}\right)},
\end{gathered}
$$

where $c_{i, t}^{c a r}$ is the costs assigned to each passenger car, and $c_{i, t}^{h g v}$ is the costs assigned to each $\mathrm{HGV}$ on road segment $i$ during time interval $t$.

\section{Case study}

The approach to internalize noise damages is applied to a real-world case study of the Greater Berlin area which was generated by Neumann et al (2014) who converted a trip-based model into an activity-based MATSim model. The transport users are modeled as "population-representative" agents based on a SrV survey (see Ahrens, 2009) and "non-population representative" agents to include additional traffic, e.g. freight, airport and tourist traffic. The transport demand was calibrated with regard to the mode shares, travel times and travel distances. In this study, the agents' executed plans of the relaxed travel demand generated by Neumann et al (2014) are used as input demand for the simulation experiments. For a better computational performance, a $10 \%$ sample of the population is used. Both the demographic and traffic related data which are required to compute noise exposures are taken from the applied case study of the Greater Berlin area. Thus, the precision of noise exposures is limited to the precision of the applied transport model. As discussed by Kaddoura et al (2015), traffic noise exposures may be computed for two different assumptions which have a substantial effect on the results.

- Assumption $\boldsymbol{A}$ : Noise damage costs are only incurred for individuals that are exposed to noise at their home activity.

- Assumption $\boldsymbol{B}$ : Noise damage costs are incurred for individuals that are exposed to noise at home, at work and education activities, i.e. school and university.

In this study, noise damage costs are mapped back to road segments and vehicle categories based on the method described in Sec. 2.2.2 and each causing agent is charged his/her contribution to the overall noise damages (internalization policy). Assuming the agents to perform activities for the predefined typical duration $\left(t_{t y p}=t_{\text {perf }}\right.$, see Sec. 2.1), the value of travel time savings (VTTS) is 10 EUR/hour. However, an agents' VTTS may be larger or smaller, depending on the agent's individual time pressure (see e.g. Nagel et al, 2014 Kaddoura and Nagel, 2016). These simulation experiments are carried out for both assumptions regarding the considered activity types, pricing policy $A$ and $B$. The internalization policies are compared with the results given in Kaddoura et al (2015), in which the simulation is run for the same case study but 
without pricing, thus the outcome is considered as the current traffic situation (base case). To allow for a comparison of the base case and the internalization policy, the transport network and simulation setup is the same as in Kaddoura et al (2015). Each simulation is run for a total of 100 iterations. During the first 80 iterations, in each iteration, $10 \%$ of the agents are enabled to experience new routes (choice set generation). During the final 20 iterations, the agents' choice sets are fixed and the selection of travel alternatives is based on a multinomial logit model. The maximum number of travel alternatives per agent is set to 4 plans. Thus, each agent's choice set may consist of several reasonable travel options. For instance, agents may use long routes with relatively low toll payments or short routes with relatively high toll payments. Applying a random utility model and allowing for more than one travel alternative per agent introduces day-to-day variability, which is found to result in an overall plausible travel behavior. The traffic flow model only accounts for road users, i.e. cars and HGV (heavy goods vehicles). Other transport modes, e.g. public transport, bike and walking, are modeled in a simplified way calculating trip travel times between two activity locations based on the beeline distance. The applied methodology focuses on noise caused by passenger cars and HGV. Further noise sources such as buses, streetcars, trains, and air planes are neglected.

\section{Results}

As shown in Tab. 3 both pricing experiments yield a reduction in noise damages of about $6 \%$ compared to the base case situation. The total travel time and travel distance are observed to increase since transport users take detours in order to avoid high toll payments on roads in residential areas. The numbers given in Tab. 3 refer to the entire day, whereas the relative changes are much higher during the morning, evening and night when noise immission thresholds are lower than during the day. The reduction in noise damage costs results from the transport users' ability to adjust their route choice decisions. That is, the network wide traffic volume, i.e. the number of starting trips per time, remains unaltered. Allowing for mode and departure time choice would presumably increase the effect. Considering all transport users within the car

Table 3: Changes in daily noise damages, travel time and driving distance due to the pricing policy

\begin{tabular}{lrr}
\hline & Pricing policy $A$ & Pricing policy $B$ \\
\hline Change in noise damage costs & $-51,436$ EUR $(-6.03 \%)$ & $-63,925$ EUR $(-5.77 \%)$ \\
Change in travel time & $+6,221$ hours $(+0.44 \%)$ & $+9,418$ hours $(+0.66 \%)$ \\
Change in driving distance & $+650,713 \mathrm{~km}(+0.82 \%)$ & $+875,011 \mathrm{~km}(+1.11 \%)$ \\
\hline
\end{tabular}

mode, the average toll per trip amounts to 0.17 EUR for assumption $A$, and 
0.22 EUR for assumption $B$. The average toll per car user amounts to 0.15 EUR for assumption $A$, and 0.20 EUR for assumption $B$. Noise costs caused by $\mathrm{HGV}$ account for about a third of the total noise damages. The average toll payed per HGV amounts to 1.46 EUR for assumption $A$, and 1.93 EUR for assumption $B$. Only accounting for the "population representative" agents (see Sec. 3), the average toll per person is 0.13 EUR for assumption $A$, and 0.16 EUR for assumption $B$. For trips until $10 \mathrm{~km}$, the average noise cost is approximately $0.015 \mathrm{EUR} / \mathrm{km}$ for assumption $A$ and $0.02 \mathrm{EUR} / \mathrm{km}$ for assumption $B$. However, for longer trips the average noise cost per kilometer is found to decrease with the distance traveled. This is explained by the fact that for a longer trip distance, the proportion of motorway usage in typically less dense populated areas is greater, and consequently the caused noise exposures are lower.

\subsection{Spatial investigation of pricing policy $A$}

\section{Traffic volumes}

Fig. 3 depicts the changes in traffic volumes during the afternoon peak between 3.00 and 4.00 p.m. as a result of the noise internalization policy $A$. Dark green and light green colored road segments indicate a decrease in traffic volume, whereas orange and red represent an increase in traffic. Furthermore, Fig. 3 incorporates the population density given in units of residents who perform a "home" activity during the considered time interval (3.00-4.00 p.m.). The changes in traffic volumes indicate two effects: First, transport users shift from minor to major roads such as to the inner-city ring road motorway. Second, indicated by the overlay of the traffic changes with the population units, transport users shift to roads in areas with lower population densities.

\section{Noise exposures}

For the same time period, Fig. 4 shows the changes in noise immission levels in $\mathrm{dB}(\mathrm{A})$ between the base case and the internalization policy $A$. In Fig. $4 \mathrm{a}$ all receiver points are shown, whereas in Fig. $4 \mathrm{~b}$, the changes in noise levels are only shown for receiver points where the number of considered population units between 3.00 and $4.00 \mathrm{p} . \mathrm{m}$. is greater than 0 . The overall noise level in the inner city area is found to decrease except for certain areas or corridors. Taking into consideration the number of affected population units, the results indicate an overall reduction in noise exposures due to the pricing policy. Overall, noise levels are observed to decrease in areas with relatively high population densities and to increase along parallel road stretches in areas with lower population densities. A decrease in noise for a relatively high population density is for example observed in Dahlem along the south-west corridor "Clayallee" which comes along with an increase in noise levels at the parallel 


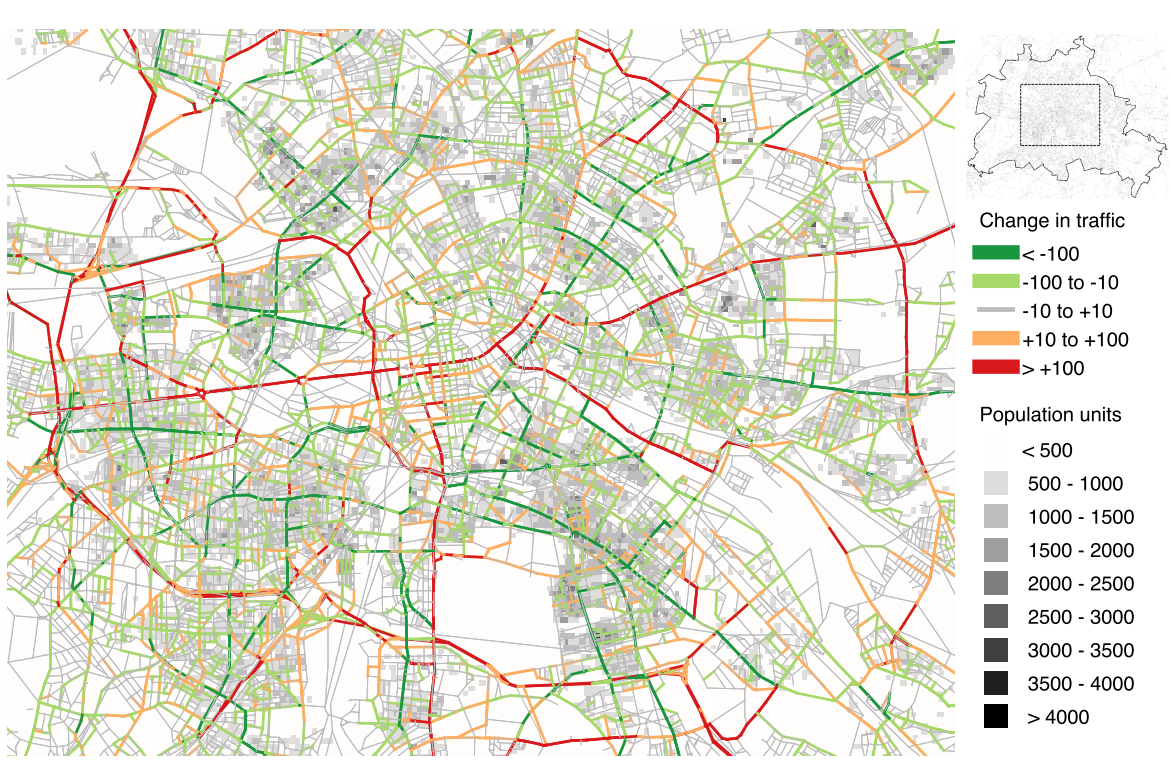

Fig. 3: Absolute changes in traffic volumes due to the pricing policy and considered population units based on assumption $A$ between 3.00 and 4.00 p.m.

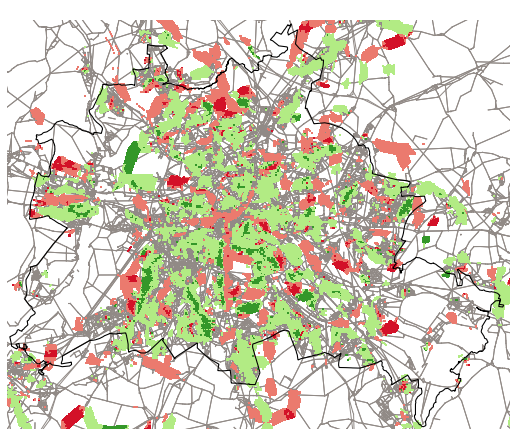

(a) all receiver points

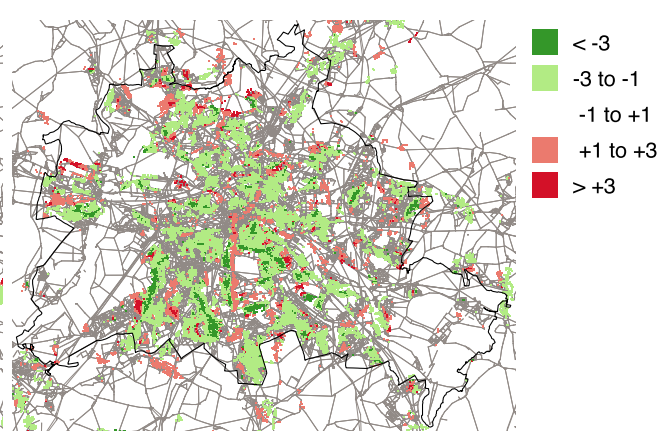

(b) population units $>0$

Fig. 4: Change in noise immission levels in $\mathrm{dB}(\mathrm{A})$ between 3.00 and 4.00 p.m. as a result of the pricing policy $A$. Changes in noise immissions below $1 \mathrm{~dB}(\mathrm{~A})$ are not displayed.

road stretch "Onkel-Tom-Straße" leading through the forest "Grunewald" 3 A noise reduction in areas with high population densities is also observed in Neukölln east of the green area "Tempelhofer Feld" or in Tempelhof along the north-south road corridor "Manteuffelstraße" and "Boelckestraße" which in return involves an increase in noise at the parallel road stretch "Tempelhofer Damm". The changes in noise levels along the inner-city ring road and the outer city motorway are found to be very low which is explained by the

3 This effectively shifts noise from a residential area into a nature reserve. If this is politically undesirable, then it will be necessary to penalize this as well in the algorithm. 
logarithmic scale of noise, i.e. the declining impact of an additional vehicle on the overall noise level for larger traffic volumes.

\section{Noise damages}

As described in Sec. 2.2.1 noise exposures are translated into damage costs considering both, the number of affected population units and the noise level. The changes in daily noise damage costs are shown in Fig. 5 . As depicted in Fig. 4. the increase in traffic on motorways does not result in a significant increase in noise damage cost. Whereas, along other road stretches, mainly in residential areas and the inner-city area, changes in noise damage costs are much larger. For several areas, a decrease in noise cost is observed to yield a smaller increase in noise cost along parallel corridors.

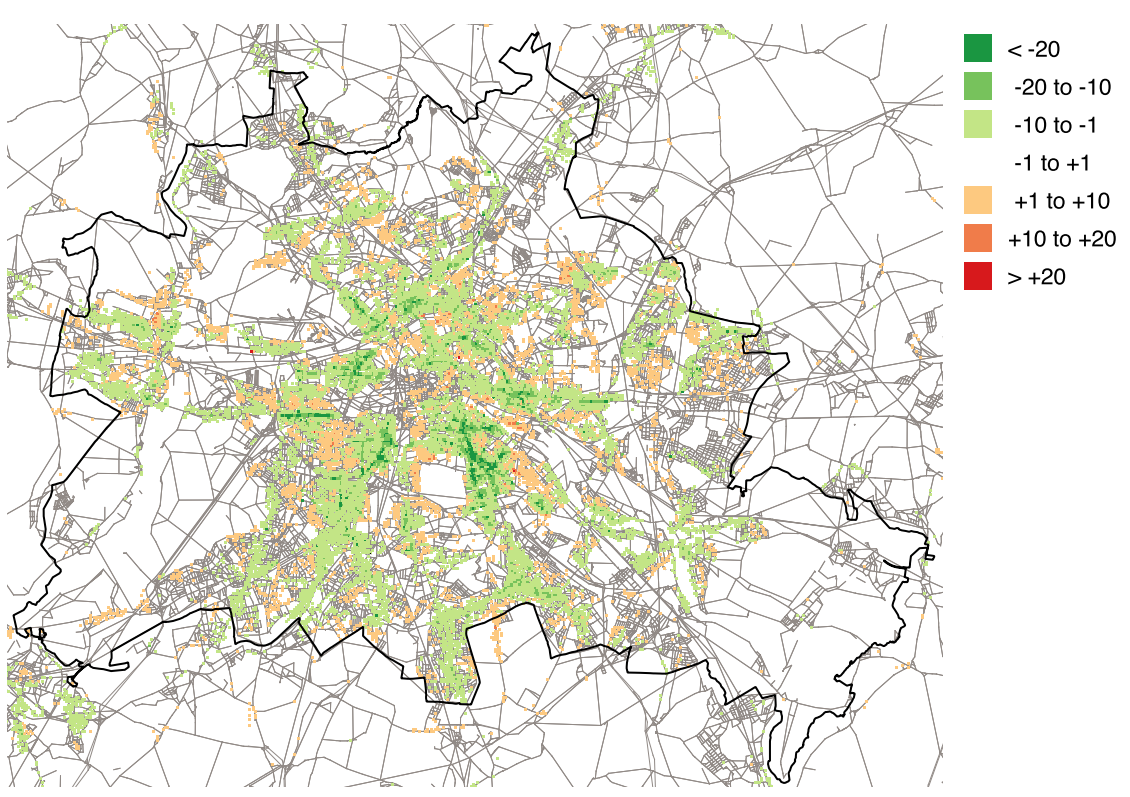

Fig. 5: Change in daily noise cost in EUR as a result of the pricing policy $A$

\subsection{Taking into consideration additional activity types}

The assumption regarding the considered activity types is found to have a substantial effect on the policy recommendations to be derived from the changes in network utilization. Fig. 6 depicts the changes in traffic between 3.00 and 4.00 p.m. as a result of the noise internalization policy $B$. A comparison of Fig. 6 with Fig. 3 reveals how the two pricing policies $A$ and $B$ differ in terms of the suggested traffic flow changes. Assuming individuals at work, school or 
university to be additionally affected by noise (pricing policy $B$ ), in the central business districts, i.e. east and west of the inner-city green area "Tiergarten", the traffic volume is much smaller than when only accounting for residential noise damages (pricing policy $A$ ).

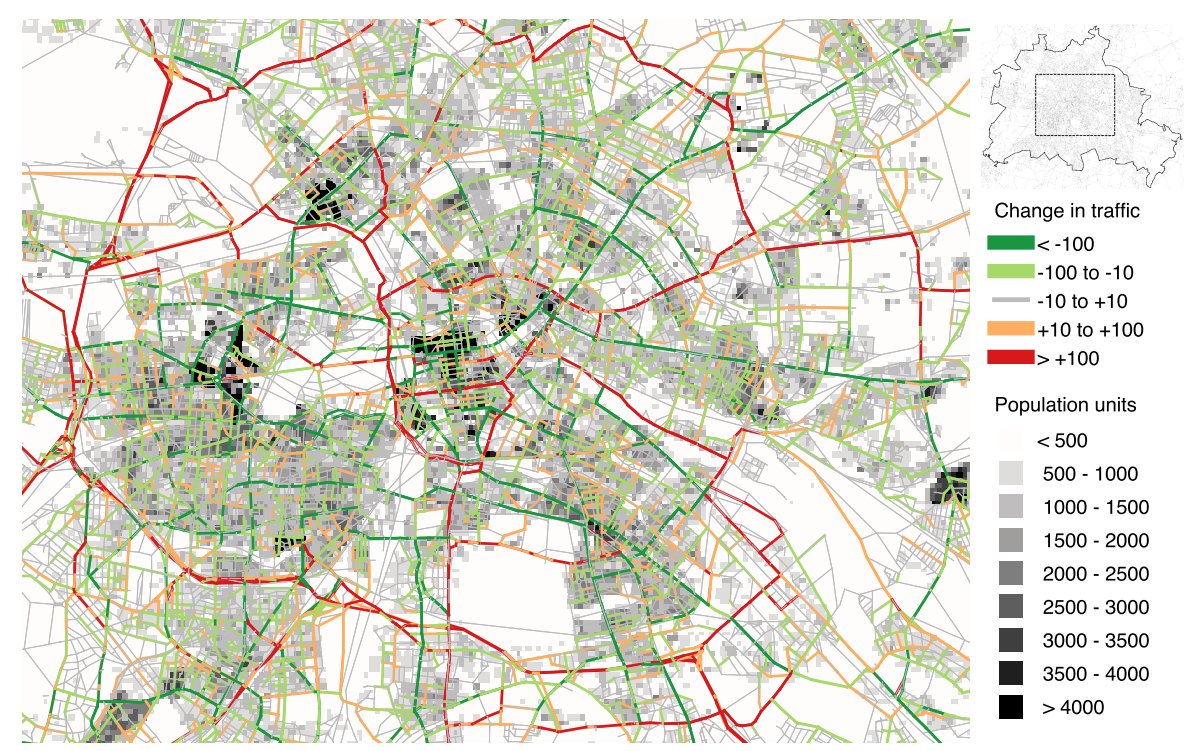

Fig. 6: Absolute changes in traffic volumes due to the pricing policy and considered population units based on assumption $B$ between 3.00 and 4.00 p.m.

\subsection{Investigation for different times of the day}

Next, the changes in traffic resulting from the pricing policy are analyzed for different times of the day. A comparison of different time periods reveals that the dynamic approach is of major importance in both pricing policies. Applying pricing policy $A$, for most road stretches, e.g. the "Hermannstraße" and "Karl-Marx-Straße" in Neukölln, during the day, the predicted traffic volume is lower compared to the base case. This is explained by a large number of residents spending the day at home. During morning, evening and night periods, the route shift effects are even stronger compared to the daytime which is explained by a large number of residents returning to their home location and thus being at home in the evening. Nevertheless, for a few road stretches, e.g. the "Hohenzollerndamm" in Wilmersdorf, an opposite change in traffic is observed for different times of the day, i.e. an increase in traffic volume during the day and a decrease in traffic in the evening, morning and night. This is explained by large temporal deviations of the population density, 
i.e. a small number of residents staying at home during the daytime and a large number of residents returning to their home location in the evening.

Applying pricing policy $B$, the time of day is found to have a very strong impact on the resulting traffic changes. As shown in Fig. 6, during the day, the system is improved by giving the incentive to drive around the central business districts, whereas, in the evening, morning and night, most individuals have left the central business districts. Consequently, the number of exposed individuals is very small and toll payments are very low during these time periods. Thus, in the morning, evening and night, the incentive of driving through the central business districts has the effect of reducing noise exposures in residential areas.

\section{Discussion}

A time-dependent and link-specific tolling system seems difficult to be implemented in real-world. Nevertheless, the proposed approach may be used to derive noise control strategies by means of traffic management. The proposed internalization approach induces changes on the demand side which reduce noise exposure costs. However, the desired demand changes may also be invoked by other means than pricing. A monetary toll can be as well interpreted as a correction term to be added to the transport user's generalized travel cost. Instead of charging a toll, for example, the speed limit could be reduced for certain roads while having the same effect on the transport users, e.g. encouraging users to take a different route. The results of the case study applied in this paper allow to draw conclusions about the desired network utilization. In particular, for each time period, traffic flows could be rearranged by making certain road stretches less attractive. By applying the presented methodology to case studies with further choice dimensions, the results would additionally indicate further demand reactions, such as temporal changes when enabling departure time choice, or modal shifts when enabling mode choice, which would further improve the overall system efficiency.

It is important to note that road priorities for action planning that are simply based on variables such as the noise level and the exposed population (see, e.g., Ruiz-Padillo et al, 2014) are difficult to be used for traffic management purposes. A road stretch may have a high priority index even though there is no meaningful alternative for the transport users, e.g. alternative route in a less densely populated area. That is, any kind of traffic management intending to reduce the noise level along a selected road stretch, for example a lower speed level or turn restrictions, may result in even higher noise exposures somewhere else. On the other hand, for less prioritized road stretches with a lower noise level and fewer residents, there may be good alternatives which allow for a reduction in noise exposures by means of traffic management, e.g. rearranging the traffic flow along parallel road stretches in less noise sensitive areas. In contrast, the presented approach accounts for the existence of meaningful alternatives. Each transport user can decide whether to avoid the toll payments by changing the travel behavior or to stick to the original travel 
behavior in case the travel alternatives involve even higher noise tolls or other travel costs. Hence, the presented noise internalization approach can be used to identify road priorities for action planning that include the existence of meaningful alternatives. A higher priority is indicated by road stretches with a predicted decrease in traffic due to noise pricing, whereas a lower priority for action planning is indicated by road stretches with no or only small changes in traffic.

In the applied pricing approach by Gerike et al (2012), tolls are computed based on each transport user's contribution to the overall noise exposure costs and total noise damages are mapped back to the causing transport users. This means, tolls correspond to the (weighted) average noise costs. As indicated by Tab. 3 in Sec. 4 the simulation outcome confirms the economic theory which says that average cost pricing may not yield a maximization of social welfare. Accounting for the change in travel distance and travel time, in both pricing policies, the increase in travel related costs is much larger than the decrease in noise damages. In a related study, an optimal noise cost pricing approach is implemented in which noise tolls are computed based on the marginal noise damage cost (see Kaddoura and Nagel, 2015). Nevertheless, the advantage of the average noise cost pricing policy by Gerike et al (2012), which is applied in the present study, is that the toll revenues are equal to total noise damage costs. Hence, affected individuals could be compensated for their noise damages. In contrast, a marginal cost pricing approach does not yield full cost recovery. This is related to the logarithmic cost structure of noise (see Sec. 2.2.1), resulting in marginal noise cost that are below average noise cost (Maibach et al, 2008).

\section{Conclusion}

In this study, an innovative noise internalization approach is presented and successfully applied to a real-world case study of the Greater Berlin area in which transport users are enabled to adjust their route choice decisions. The contribution of the presented approach is that noise exposure tolls are computed by explicitly accounting for the temporal and spatial variation of the noise level and exposed population. Moreover, the activity-based simulation approach allows to go beyond residential noise exposures and additionally account for individuals that are exposed to traffic noise at work, school or university. Iteratively, transport users are enabled to react to local tolls which correspond to the transport user's contribution to the overall noise exposures. Hence, the proposed approach can be used to investigate traffic control strategies.

Applying the pricing approach to the Berlin case study reveals that the overall noise exposures decrease by about $6 \%$ even though transport users are only enabled to adjust their routes and the number of trip departures per time remains unaltered. As a reaction to the pricing policy, transport users shift from minor to major roads and take detours in order to avoid high toll payments in areas with high population densities. Thus, the total travel time 
and travel distance increase. Consequently, noise levels are reduced in areas with high population densities, whereas noise levels in less dense populated areas increase. As indicated by Kaddoura et al (2015), the assumption where, i.e. at which activities, individuals are affected by traffic noise is found to have a substantial effect on the policy recommendations. Going beyond residential noise exposures and assuming individuals at work, school or university to be additionally affected by noise, significantly reduces the traffic volume in the central business districts. Moreover, the dynamic approach of calculating noise levels and population exposures is found to be of major importance for traffic management strategies. In particular, when noise exposures at work, school or university are accounted for, noise exposures are reduced by giving the incentive to drive around the central business districts during the daytime. In contrast, during the morning, evening and night, noise exposures are reduced by encouraging transport users to drive through the central business districts. Overall, this study may be seen as a first step towards a more sophisticated noise control by means of intelligent traffic management.

The presented methodology can easily be extended towards differentiated cost rates and threshold values for various activity types or population subgroups, which would improve the quantification of noise exposure costs and noise tolls. As addressed by Gühnemann et al (2014), recreational activities may be incorporated which is straightforward using an activity-based approach. Moreover, the model could be extended to account for on-road exposures which are in particular relevant for pedestrians and cyclists. A major task for future studies is to use the presented methodology to identify road stretches with high priorities for action planning. This prioritization can then be used to design a policy for certain areas or road stretches which should be evaluated based on the changes in noise damages and travel related cost. In future studies, the presented noise pricing methodology will be combined with existing pricing approaches for other external cost components that are based on the same simulation framework such as Kaddoura (2015) for congestion and Kickhöfer and Nagel (2013) for air pollution.

Acknowledgements The authors are grateful to three anonymous reviewers for their constructive comments and suggestions. A previous version of this paper was presented at the 4th Symposium of the European Association for Research in Transportation (hEART 2015) in Copenhagen, Denmark.

\section{References}

16 BImSchV. Verkehrlärmschutzverordnung vom 12. Juni 1990 (BGBI. I S. 1036), die durch Artikel 1 der Verordnung vom 18. Dezember 2014 (BGBI I S. 2269) geändert worden ist. 16. Verordnung zur Durchführung des Bundes-Immissionsschutzgesetzes

2002/49/EC. Directive of the european parliament and of the council of 25 june 2002 relating to the assessment and management of environmental noise. Official Journal of the European Communities 
Agarwal A, Zilske M, Rao K, Nagel K (2015). An elegant and computationally efficient approach for heterogeneous traffic modelling using agent based simulation. Procedia Computer Science 52(C):962-967, doi: 10.1016/j.procs. 2015.05.173

Ahrens GA (2009). Endbericht zur Verkehrserhebung Mobilität in Städten SrV 2008 in Berlin. Tech. rep., Technische Universität Dresden

Arnott R, de Palma A, Lindsey R (1994). The welfare effects of congestion tolls with heterogeneous commuters. Journal of Transport Economics and Policy 28:139-161

Babisch W, Pershagen G, Selander J, Houthuijs D, Breugelmans O, Cadum E, Vigna-Taglianti F, Katsouyanni K, Haralabidis AS, Dimakopoulou K, Sourtzi P, Floud S, Hansell AL (2013). Noise annoyance - a modifier of the association between noise level and cardiovascular health? Science of The Total Environment 452-453:50-57, doi: 10.1016/j.scitotenv.2013.02.034

BVU, IVV, PLANCO (2003). Bundesverkehrswegeplan 2003 - Die gesamtwirtschaftliche Bewertungsmethodik [Federal transport infrastructure plan 2003 - the economic evaluation methodology]. Final report for research project FE-Nr. 96.0790/2003, Beratergruppe Verkehr+Umwelt, Ingenieurgruppe IVV, Planco Consulting GmbH, funded by BMVBW

Charypar D, Nagel K (2005). Generating complete all-day activity plans with genetic algorithms. Transportation 32(4):369-397, doi: 10.1007/ s11116-004-8287-y

de Palma A, Lindsey R (2004). Congestion pricing with heterogeneous travelers: A general-equilibrium welfare analysis. Networks and Spatial Economics 4(2):135-160, doi: 10.1023/B:NETS.0000027770.27906.82

DEFRA (2015). Noise mapping england. Department for Envirionment, Food and Rural Affairs, http://services.defra.gov.uk/wps/portal/noise/ maps, accessed 27 January 2015

DIN 4109, Beiblatt 1. Sound insulation in buildings; construction examples and calculation methods [Schallschutz im Hochbau; Ausführungsbeispiele und Rechenverfahren]. Deutsches Institut für Normung e.V., 11/1989

DIN EN ISO 11690-1. Acoustics - recommended practice for the design of lownoise workplaces containing machinery - part 1: Noise control strategies (iso 11690-1:1996); German Version EN ISO 11690-1:1996. Deutsches Institut für Normung e.V., 02/1997

FGSV (1992). Richtlinien für den Lärmschutz an Straßen (RLS), Ausgabe 1990, Berichtigte Fassung. Forschungsgesellschaft für Straßen- und Verkehrswesen, http://www.fgsv.de

FGSV (1997). Empfehlungen für Wirtschaftlichkeitsuntersuchungen an Straßen (EWS). Aktualisierung der RAS-W 86. Forschungsgesellschaft für Straßen- und Verkehrswesen, http://www.fgsv.de

Friesz TL, Bernstein D, Kydes N (2004). Dynamic congestion pricing in disequilibrium. Networks and Spatial Economics 4(2):181-202, doi: 10.1023/B: NETS.0000027772.43771.94

Gawron C (1998). An iterative algorithm to determine the dynamic user equilibrium in a traffic simulation model. International Journal of Modern 
Physics C 9(3):393-407

Gerike R, Hülsmann F, Heidegger F, Friedemann J, Becker T (2012). Quantification and mapping external noise costs back to transport users - development of an integrated urban modelling approach. In: Proceedings of the European Conference on Noise Control (EURONOISE)

Gühnemann A, Koh A, Shepherd S (2014). Optimal charging strategies under conflicting objectives for the protection of sensitive areas: A case study of the trans-pennine corridor. Networks and Spatial Economics pp 1-28, doi: 10.1007/s11067-013-9211-9

Gulliver J, Morley D, Vienneau D, Fabbri F, Bell M, Goodman P, Beevers S, Dajnak D, Kelly FJ, Fecht D (2015). Development of an open-source road traffic noise model for exposure assessment. Environmental Modelling \& Software doi: http://dx.doi.org/10.1016/j.envsoft.2014.12.022

Hatzopoulou M, Miller EJ (2010). Linking an activity-based travel demand model with traffic emission and dispersion models: Transport's contribution to air pollution in Toronto. Transportation Research Part D: Transport and Environment 15(6):315-325, doi: 10.1016/j.trd.2010.03.007

Ising H, Günther T, Havestedt C, Krause C, Markert B, Melchert HU, Schoknecht G, Thefeld W, Tietze KW (1996). Lärmbeurteilung - extraaurale wirkungen. Arbeitswissenschaftliche Erkenntnisse Nr. 98, Bundesanstalt für Arbeitsschutz und Arbeitsmedizin, Dortmund

Kaddoura I (2015). Marginal congestion cost pricing in a multi-agent simulation: Investigation of the greater Berlin area. Journal of Transport Economics and Policy 49(4):560-578

Kaddoura I, Nagel K (2015). Activity-based computation of marginal noise exposure costs: Impacts for traffic management. VSP Working Paper 15-13, TU Berlin, Transport Systems Planning and Transport Telematics

Kaddoura I, Nagel K (2016). Agent-based congestion pricing and transport routing with heterogeneous values of travel time savings. VSP Working Paper 16-01, TU Berlin, Transport Systems Planning and Transport Telematics

Kaddoura I, Kröger L, Nagel K (2015). An activity-based and dynamic approach to calculate road traffic noise damages. VSP Working Paper 15-05, TU Berlin, Transport Systems Planning and Transport Telematics

Kickhöfer B, Kern J (2015). Pricing local emission exposure of road traffic: An agent-based approach. Transportation Research Part D: Transport and Environment 37:14-28, doi: 10.1016/j.trd.2015.04.019

Kickhöfer B, Nagel K (2013). Towards high-resolution first-best air pollution tolls. Networks and Spatial Economics pp 1-24, doi: 10.1007/ s11067-013-9204-8

Lam K, Chung YT (2012). Exposure of urban populations to road traffic noise in hong kong. Transportation Research Part D: Transport and Environment 17:466-472, doi: $10.1016 /$ j.trd.2012.05.003

Lin X, Tampère CMJ, Viti F, Immers B (2014). The Cost of Environmental Constraints in Traffic Networks: Assessing the Loss of Optimality. Networks and Spatial Economics pp 1-21, doi: 10.1007/s11067-014-9228-8 
Maibach M, Schreyer D, Sutter D, van Essen H, Boon B, Smokers R, Schroten A, Doll C, Pawlowska B, Bak M (2008). Handbook on estimation of external costs in the transport sector. Tech. rep., CE Delft, Internalisation Measures and Policies for All external Cost of Transport (IMPACT)

Murphy E, King EA (2010). Strategic environmental noise mapping: Methodological issues concerning the implementation of the eu environmental noise directive and their policy implications. Environment International 36(3):290 - 298, doi: 10.1016/j.envint.2009.11.006

Nagel K, Flötteröd G (2012). Agent-based traffic assignment: Going from trips to behavioural travelers. In: Pendyala R, Bhat C (eds) Travel Behaviour Research in an Evolving World - Selected papers from the 12th international conference on travel behaviour research, International Association for Travel Behaviour Research, chap 12, pp 261-294

Nagel K, Kickhöfer B, Joubert JW (2014). Heterogeneous tolls and values of time in multi-agent transport simulation. Procedia Computer Science 32:762-768, doi: 10.1016/j.procs.2014.05.488

Neumann A, Balmer M, Rieser M (2014). Converting a static trip-based model into a dynamic activity-based model to analyze public transport demand in Berlin. In: Roorda M, Miller E (eds) Travel Behaviour Research: Current Foundations, Future Prospects, International Association for Travel Behaviour Research (IATBR), chap 7, pp 151-176

Nielsen HL, Bendtsen H, Kielland J, Bechmann E, Ljunggren S, Göransson C, Strömmer K, Paikkala SL, Jansson A, Tómasson P, Kragh J, Jonasson H, Sandberg U, Storheier S, Parmanen J (1996). Road Traffic Noise. Nordic Prediction Method. TemaNord, The Nordic Council of Ministers

Raney B, Nagel K (2006). An improved framework for large-scale multi-agent simulations of travel behaviour. In: Rietveld P, Jourquin B, Westin K (eds) Towards better performing European Transportation Systems, Routledge, London, pp 305-347

Raney B, Cetin N, Völlmy A, Vrtic M, Axhausen K, Nagel K (2003). An agent-based microsimulation model of Swiss travel: First results. Networks and Spatial Economics 3(1):23-41, doi: 10.1023/A:1022096916806

RPS (2011). Roma to brisbane pipeline - dalby compressor station upgrade: Environmental management plan. Tech. rep., RPS Australia East Pty Ltd, Sonus Pty Ltd

Ruiz-Padillo A, Torija AJ, Ramos-Ridao A, Ruiz DP (2014). A methodology for classification by priority for action: Selecting road stretches for network noise action plans. Transportation Research Part D: Transport and Environment 29:66-78, doi: 10.1016/j.trd.2014.04.002

SenStadt (2012). Environmental Atlas Berlin; Strategic noise maps (Edition 2012); Calculation results / Tabular evaluations. Senatsverwaltung für Stadtentwicklung Berlin, http://www.stadtentwicklung.berlin.de/umwelt/ umweltatlas/e_tab/ta705_04-06.xls, accessed 26 January 2015

Stassen KR, Collier P, Torfs R (2008). Environmental burden of disease due to transportation noise in flanders (belgium). Transportation Research Part D: Transport and Environment 13:355-358, doi: 10.1016/j.trd.2008.04.003 
Tenaileau QM, Bernard N, Pujol S, Houot H, Joly D, Mauny F (2015). Assessing residential exposure to urban noise using environmental models: does the size of the local living neighborhood matter? Journal of Exposure Science and Environmental Epidemiology 25:89-96, doi: 10.1038/jes.2014.33

Vickrey W (1969). Congestion theory and transport investment. The American Economic Review 59(2):251-260

WG-AEN (2006). Good practice guide for strategic noise mapping and the production of associated data on noise exposure. Tech. rep., European Commission Working Group Assessment of Exposure to Noise, position Paper, Version 2, Final Draft

WHO Europe (2009). Night noise guidelines for europe. Tech. rep., World Health Organization, http://www.euro.who.int/__data/assets/ pdf_file/0017/43316/E92845.pdf

WHO Europe (2011). Burden of disease from environmental noise. quantification of health life years lost in europe. Tech. rep., World Health Organisation, http://www.euro.who.int/__data/assets/pdf_file/0008/ 136466/e94888.pdf 